\title{
A randomised trial in Mali of the effectiveness of weekly iron supplements given by teachers on the haemoglobin concentrations of schoolchildren
}

\author{
Andrew Hall ${ }^{1}$, Natalie Roschnik ${ }^{2,3, *}$, Fatimata Ouattara ${ }^{4}$, Idrissa Touré ${ }^{4}$, Fadima Maiga ${ }^{2}$, \\ Moussa Sacko ${ }^{4}$, Helen Moestue ${ }^{1}$ and Mohamed Ag Bendech ${ }^{4}$ \\ ${ }^{1}$ Helen Keller International, PO Box 6066, Gulshan, 1212 Dhaka, Bangladesh: ${ }^{2}$ Save the Children (USA), BP 3105 , \\ Bamako, Mali: ${ }^{3}$ Present address: Save the Children, 54 Wilton Road, Westport, CT 0680, USA: ${ }^{4}$ Institut National de \\ Recherche en Santé Publique, BP 1771, Bamako, Mali: ${ }^{5}$ Helen Keller International, BP 1557, Bamako, Mali
}

Submitted 22 August 2001: Accepted 14 December 2001

\begin{abstract}
Objective: To assess the effect on the haemoglobin concentrations of schoolchildren of weekly iron tablets administered by teachers.

Design: Sixty schools were randomly assigned to two groups: in 30 schools children were given weekly for 10 weeks a tablet providing $65 \mathrm{mg}$ of iron and $0.25 \mathrm{mg}$ of folic acid; in the other 30 schools no iron tablets were given. All children were dewormed and given vitamin A before the study began. The haemoglobin concentration of up to 20 randomly selected children in each school was estimated before and 2 weeks after the end of treatment.

Setting: Rural community schools in Kolondieba district of Mali.

Subjects: Some 1113 schoolchildren aged 6-19 years with a mean of 11.4 years.

Results: The haemoglobin concentration of treated children rose on average by $1.8 \mathrm{gl}^{-1}(P<0.001)$ and the prevalence of anaemia fell by $8.2 \%(P<0.001)$; in untreated children the haemoglobin concentration fell by an average of $-2.7 \mathrm{gl}^{-1}$ $(P<0.001)$ and the prevalence of anaemia rose by $9.4 \%(P<0.001)$. The fall in haemoglobin concentration among untreated girls of $-4.0 \mathrm{gl}^{-1}$ was greater than in untreated boys $\left(-0.3 \mathrm{~g} \mathrm{l}^{-1}, P<0.001\right)$.

Conclusions: Weekly iron tablets given by teachers prevented a general fall in the haemoglobin concentrations of untreated children, and led to a small but statistically significant rise among treated children $(P<0.001)$. Young children benefited more than children aged $\geq 12$ years, and girls benefited more than boys.
\end{abstract}

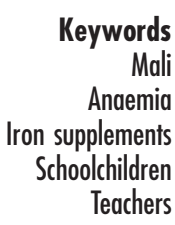

The non-formal education sector is providing a growing solution to the problem of poor enrolment in basic education, especially in south Asia and sub-Saharan Africa. Non-formal schools are typically small, with 3060 pupils in one or two grades; they are often established by non-governmental organisations (NGOs) and are then funded and managed by the community; they generally employ local people as teachers who have not been trained in the government education system; instruction is usually given in the local language; and the schools are located in the villages they serve, which makes them accessible to all children. These schools provide an alternative to the government education system and also offer an opportunity to provide health services to schoolchildren.

A recent survey of the haemoglobin concentrations of schoolchildren in eight countries in Africa and Asia reported that anaemia was common, especially in subSaharan Africa ${ }^{1}$. The prevalence of anaemia among children in non-formal schools in Mali was 56\% and, as in most countries, children aged 7-11 years had a lower mean haemoglobin concentration than older children ${ }^{1}$. Anaemia in this age group is associated with impaired growth and physical fitness and with poor results in tests of educational achievement and cognitive function ${ }^{2-5}$.

The school system offers a potential means to tackle the problem of anaemia in schoolchildren as it provides an existing infrastructure to deliver nutritional supplements to sites where children congregate daily for around twothirds of the year, and provides educated staff who could administer treatments. The aim of the study described here was to examine the effectiveness with which teachers in non-formal schools could deliver weekly iron supplement to their pupils. 


\section{Subjects and methods}

The study was undertaken in Kolondieba district in Sikasso Region of south-eastern Mali, where Save the Children (USA) has established 145 non-formal, community schools. A typical school has two grades, a new grade is created every three years, and children receive six years of education. Sixty schools were selected for the study as follows. All schools that had children in the 2 nd or 4 th grade of education were listed in order to provide schools in which children could read and write for a separate study of educational achievements (not reported here), and then 60 were randomly selected. These 60 schools were then randomly assigned to either a treatment or a comparison group. Within each school up to 10 girls and 10 boys were randomly selected for study from the grade, if there were sufficient numbers.

The study was done with the permission of the Ministry of Health. Permission to involve children in the study was obtained in every village from the local chief and the school management committee. The purpose of the study was explained to the parents and pupils by the teacher and the school management committee beforehand, and the explanation was repeated on the day that blood was taken by the survey team from the Ministry of Health and Save the Children, and consent was obtained.

The baseline survey was done in January 2000. Capillary blood samples were taken from a finger-prick by trained haematologists from the Ministry of Health from the 20 randomly selected children in each school, and the concentration of haemoglobin was estimated using Hemocue haemoglobinometers (Hemocue, Sweden). The Hemocues were checked every day using the internal cuvette. Any child with severe anaemia (haemoglobin concentration $\leq 80 \mathrm{gl}^{-1}$ ) was excluded from the study and treated with ferrous sulphate.

All children in every school were treated before the intervention began with $400 \mathrm{mg}$ of albendazole (Medpharm, Washington DC, USA) to expel intestinal parasites, because hookworm is endemic in Sikasso Region ${ }^{6}$. A week later all children in every school were given a single capsule of $200000 \mathrm{IU}$ of vitamin A (Holden Medical, WEZEP, the Netherlands), because a survey had found that $4.5 \%$ of schoolchildren had reported nightblindness ${ }^{7}$. This amount of retinol is recommended as a treatment and to provide reserves for at least 3 months $^{8}$. Retinol supplements have been shown to improve the haemoglobin concentrations of schoolchildren in Tanzania without giving iron? ${ }^{9}$, so vitamin A was given to ensure that this was not a factor limiting any improvement in haemoglobin concentration.

All children in the 30 treatment schools were then given by their teachers every week for 10 weeks a single tablet of $200 \mathrm{mg}$ ferrous sulphate (providing $65 \mathrm{mg}$ of elemental iron) and $0.25 \mathrm{mg}$ folic acid (Weifa AS, Oslo, Norway). The teachers were trained on the causes of anaemia and the possible side effects of giving iron, and were given sheets to record every child who received an iron tablet once a week.

Between 14 and 16 weeks after the baseline survey, and about two weeks after iron supplementation had finished, a capillary blood sample was taken again by a finger-prick from the same children in each school and the haemoglobin concentration was estimated using a Hemocue haemoglobinometer. To check that children had been given iron supplements, each child was interviewed and asked how many tablets had been received. Most children reported that they had been given tablets every week.

Children were classified as anaemic using the thresholds recommended by the World Health Organization (2001): children aged 5-11.99 years, $<115 \mathrm{gl}^{-1}$; children aged 12.0-14.99 years, $<120 \mathrm{gl}^{-1}$; boys aged $\geq 15$ years, $130 \mathrm{gl}^{-1}$; and girls aged $\geq 15$ years, $120 \mathrm{gl}^{-1}$.

Data were entered into a computer using Epilnfo version 5 and analysed using SPSS version 9. Differences between means were tested for statistical significance using Student's $t$-test, and differences between proportions were tested using the Chi-square test. A linear regression model was developed to examine the factors associated with the change in haemoglobin concentration over the study period.

\section{Results}

A total of 20 schools with 2nd grade classes and 40 schools with 4th grade classes took part in the study. Data recorded by teachers indicated that coverage was good: $83 \%$ of children were given all 10 tablets and 91\% received at least nine tablets.

Blood samples were collected from 1201 children at the baseline survey and 1113 children $14-16$ weeks later. The haemoglobin concentration of the 88 children who dropped out of the study or did not provide a second blood sample was not significantly different at baseline from those children who remained in the study (112.9 vs. $114.9 \mathrm{gl}^{-1}, P=0.16$ ). Data were analysed only for those children who provided both blood samples.

Table 1 shows the mean and standard deviations of the haemoglobin concentrations of children in both study groups by sex and in total at both surveys. There were no significant differences between study groups at baseline. The mean haemoglobin concentrations of children given iron supplements rose by $1.8 \mathrm{gl}^{-1}$ over the study period while the concentrations of untreated children fell by $-2.7 \mathrm{gl}^{-1}$. Both these changes were statistically significant (Table 1). The magnitude of these differences was greater for girls than for boys: although the haemoglobin concentration of girls given iron rose by $1.6 \mathrm{~g} \mathrm{l}^{-1}$ compared with $2.0 \mathrm{gl}^{-1}$ for boys, the haemoglobin concentration of untreated girls fell by an average of $-4.0 \mathrm{gl}^{-1}$ compared with a fall of $-1.3 \mathrm{gl}^{-1}$ for boys. 
Table 1 The mean and standard deviation (SD) haemoglobin concentrations in $\mathrm{gl}^{-1}$ of children in the intervention (weekly iron supplements for up to 10 weeks) and comparison group (no iron supplements) at baseline and re-survey by sex and in total, and the mean difference in each group between surveys. The statistical significance of differences between study groups is shown in rows and that between surveys is shown in columns

\begin{tabular}{|c|c|c|c|c|c|c|c|c|c|c|c|c|c|c|c|}
\hline & \multicolumn{5}{|c|}{ Boys } & \multicolumn{5}{|c|}{ Girls } & \multicolumn{5}{|c|}{ Total } \\
\hline & \multicolumn{2}{|c|}{$\begin{array}{l}\text { Intervention } \\
(n=280)\end{array}$} & \multicolumn{2}{|c|}{$\begin{array}{l}\text { Control } \\
(n=281)\end{array}$} & \multirow[b]{2}{*}{$P$} & \multicolumn{2}{|c|}{$\begin{array}{l}\text { Intervention } \\
(n=271)\end{array}$} & \multicolumn{2}{|c|}{$\begin{array}{l}\text { Control } \\
(n=281)\end{array}$} & \multirow[b]{2}{*}{$P$} & \multicolumn{2}{|c|}{$\begin{array}{l}\text { Intervention } \\
(n=551)\end{array}$} & \multicolumn{2}{|c|}{$\begin{array}{c}\text { Control } \\
(n=562)\end{array}$} & \multirow[b]{2}{*}{$P$} \\
\hline & Mean & SD & Mean & SD & & Mean & SD & Mean & SD & & Mean & SD & Mean & SD & \\
\hline Baseline & 113.9 & 12.7 & 113.5 & 12.5 & 0.8 & 115.4 & 13.2 & 117.0 & 12.7 & 0.13 & 114.6 & 13.0 & 115.3 & 12.7 & 0.38 \\
\hline Re-survey & 115.9 & 12.9 & 112.2 & 12.4 & $<0.001$ & 117.0 & 12.4 & 113.0 & 13.1 & $<0.001$ & 116.4 & 12.7 & 112.6 & 12.7 & $<0.001$ \\
\hline $\begin{array}{l}\text { Difference } \\
P\end{array}$ & $\begin{array}{l}2.0 \\
0.007\end{array}$ & 12.5 & $\begin{array}{l}-1.3 \\
0.091\end{array}$ & 13.2 & 0.002 & $\begin{array}{l}1.6 \\
0.034\end{array}$ & 12.5 & $\begin{array}{l}-4.0 \\
<0.001\end{array}$ & 13.3 & $<0.001$ & $\begin{array}{c}1.8 \\
<0.001\end{array}$ & 12.5 & $\begin{array}{l}-2.7 \\
<0.001\end{array}$ & 13.3 & $<0.001$ \\
\hline
\end{tabular}

Figure 1 shows the distributions of haemoglobin concentrations by study group at both surveys. It shows that, over the study period, values fell in the control group and improved among children given iron supplements, so that the distributions of haemoglobin concentrations diverged.

Table 2 shows the percentage of children classified as anaemic at each survey by sex and in total. Overall the
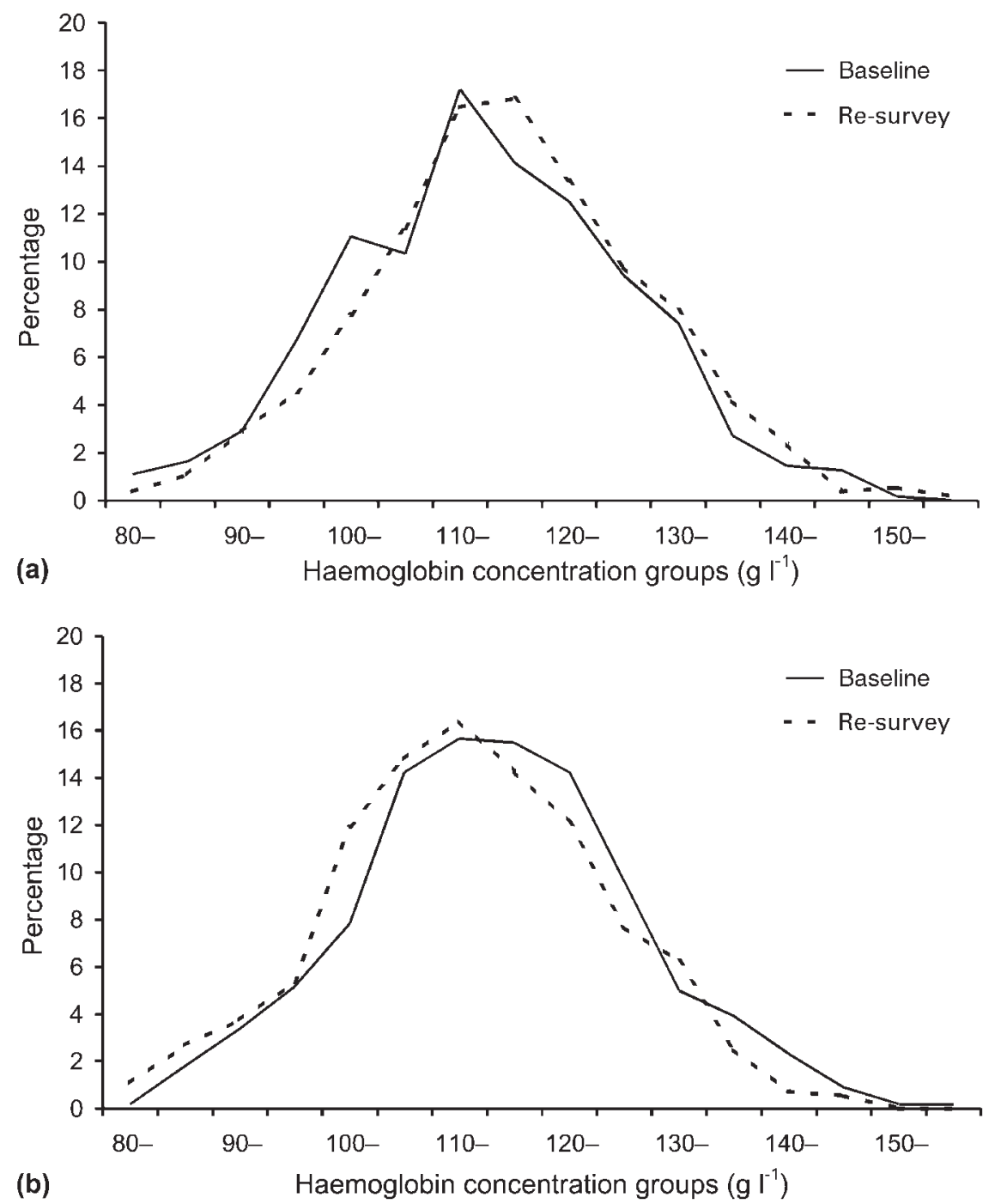

Fig. 1 (a) The distribution of haemoglobin concentrations in children in the intervention group (weekly iron supplements for 10 weeks) at baseline and re-survey 14-16 weeks later. (b) The distribution of haemoglobin concentrations in children in the control group (no iron supplements) at baseline and re-survey 14-16 weeks later 
Table 2 The number and percentage of children classified as anaemic in the intervention group (weekly iron supplements for up to 10 weeks) and comparison group (no iron supplements) at baseline and re-survey by sex and in total, and the difference in percentages between surveys. The statistical significance of differences in proportions between study groups is shown in rows, and that between surveys is shown in columns

\begin{tabular}{|c|c|c|c|c|c|c|c|c|c|c|c|c|c|c|c|}
\hline & \multicolumn{5}{|c|}{ Boys } & \multicolumn{5}{|c|}{ Girls } & \multicolumn{5}{|c|}{ Total } \\
\hline & \multicolumn{2}{|c|}{$\begin{array}{l}\text { Intervention } \\
(n=280)\end{array}$} & \multicolumn{2}{|c|}{$\begin{array}{l}\text { Control } \\
(n=281)\end{array}$} & \multirow[b]{2}{*}{$P$} & \multicolumn{2}{|c|}{$\begin{array}{l}\text { Intervention } \\
(n=271)\end{array}$} & \multicolumn{2}{|c|}{$\begin{array}{c}\text { Control } \\
(n=281)\end{array}$} & \multirow[b]{2}{*}{$P$} & \multicolumn{2}{|c|}{$\begin{array}{l}\text { Intervention } \\
(n=551)\end{array}$} & \multicolumn{2}{|c|}{$\begin{array}{c}\text { Control } \\
(n=562)\end{array}$} & \multirow[b]{2}{*}{$P$} \\
\hline & No. & $\%$ & No. & $\%$ & & No. & $\%$ & No. & $\%$ & & No. & $\%$ & No. & $\%$ & \\
\hline Baseline & 177 & 63.2 & 170 & 60.5 & 0.51 & 141 & 52.0 & 133 & 47.3 & 0.27 & 318 & 57.7 & 303 & 53.9 & 0.20 \\
\hline Re-survey & 149 & 53.2 & 185 & 65.8 & 0.002 & 124 & 45.8 & 171 & 60.9 & $<0.001$ & 273 & 49.5 & 356 & 63.3 & $<0.001$ \\
\hline $\begin{array}{l}\text { Difference } \\
P\end{array}$ & $\begin{array}{l}-28 \\
<0.001\end{array}$ & -10.0 & $\begin{array}{l}15 \\
<0.001\end{array}$ & 5.3 & & $\begin{array}{l}-17 \\
<0.001\end{array}$ & -6.3 & $\begin{array}{l}38 \\
<0.001\end{array}$ & 13.6 & & $\begin{array}{l}-45 \\
<0.001\end{array}$ & -8.2 & $\begin{array}{l}53 \\
<0.001\end{array}$ & 9.4 & \\
\hline
\end{tabular}

percentage of children classified as anaemic fell by $8 \%$ in the treatment group and increased by $9 \%$ in the untreated group. Again the difference in changes was greater for girls than for boys: the percentage of girls classified as anaemic fell by $6 \%$ in the treatment group compared with $10 \%$ for boys, but the percentage of untreated girls classified as anaemic rose by $14 \%$ compared with only $5 \%$ of boys.

Figure 2 shows for each study group the relationship between the mean change in haemoglobin concentration and the initial haemoglobin concentration grouped in ranges to give an arbitrary minimum sample size of at least 10 subjects. The figure shows that the haemoglobin concentration of children with low values at the baseline survey rose on average over the study while those of children with high values fell on average.

Table 3 shows the main variables introduced into a general linear model in which the dependent variable was the difference in haemoglobin concentration between the baseline and re-survey. The sex of the subject was not statistically significant but the treatment, age and initial haemoglobin concentration were all significant (Table 2).

Because younger children had a lower mean initial haemoglobin concentration than older children $(<12$ years, $n=717, \quad 112.8 \mathrm{gl}^{-1}$ vs. $\geq 12$ years, $n=392$, $118.9 \mathrm{gl}^{-1}, P<0.001$ ), the impact of the intervention was greater on the younger age group. The haemoglobin concentration of treated children aged $<12$ years rose by an average of $3.0 \mathrm{~g} \mathrm{l}^{-1}$ compared with a fall of $-3.0 \mathrm{~g} \mathrm{l}^{-1}$ in children in the untreated group $(P<0.001)$, whereas for children aged 12 years or older there was no significant difference between treatment groups in the change in haemoglobin concentration (treated $0.3 \mathrm{gl}^{-1} \mathrm{vs}$. untreated $\left.-2.1 \mathrm{gl}^{-1}, P=0.164\right)$.

\section{Discussion}

This study has shown that teachers in non-formal schools in Mali can give weekly iron tablets over a 10-week period to their pupils and bring about a small but significant increase in the mean haemoglobin concentration in addition to preventing a significant fall in the haemoglobin concentration of the untreated control group. Over the study period the mean haemoglobin concentration of children in the 30 control schools where iron tablets were not given fell on average by $-2.7 \mathrm{~g} \mathrm{l}^{-1}$ (Table 1) and the prevalence of anaemia rose from $54 \%$ to $63 \%$ (Table 2). In

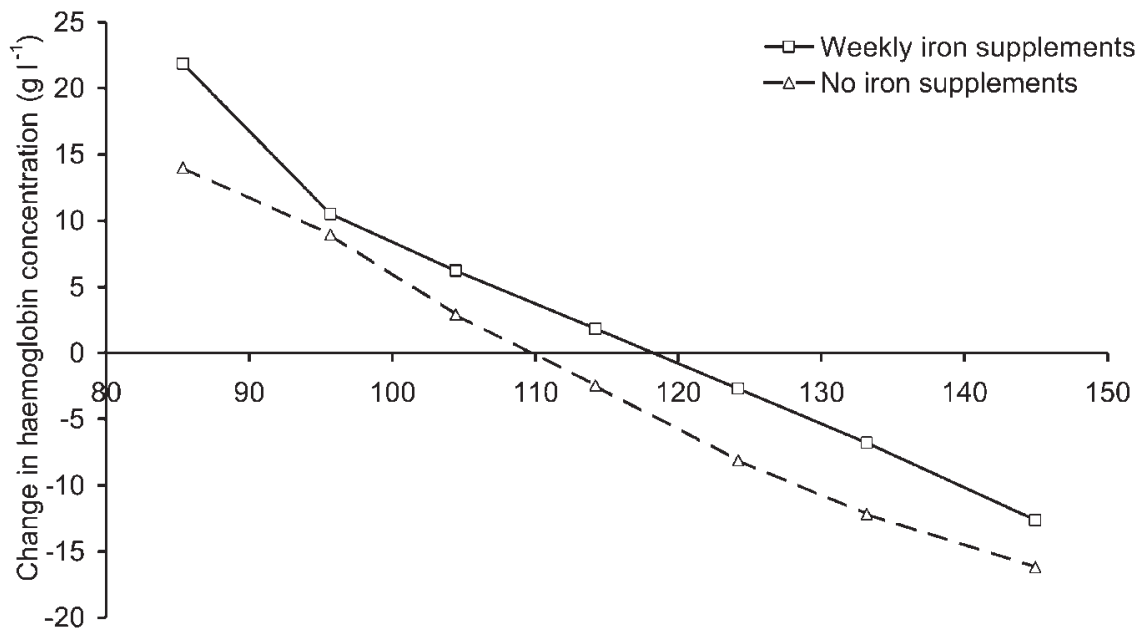

Haemoglobin concentration at baseline $\left(\mathrm{g} \mathrm{I}^{-1}\right)$

Fig. 2 The mean change in the haemoglobin concentration of children plotted against their initial haemoglobin concentration, grouped so that there was an arbitrary minimum of 10 children per group 
Table 3 The results of a linear regression model in which the dependent variable was the difference between the haemoglobin concentrations in $\mathrm{gl}^{-1}$ of schoolchildren in 30 schools in Mali given weekly iron supplements and children in 30 schools who did not receive iron

\begin{tabular}{lccrc}
\hline Variable & $\begin{array}{c}\text { Coefficient } \\
(B)\end{array}$ & $\begin{array}{c}\text { Standard } \\
\text { error }\end{array}$ & \multicolumn{1}{c}{$t$} & $P$ \\
\hline Treatment given & -0.397 & 0.066 & -6.021 & 0.001 \\
Sex & -0.020 & 0.066 & -0.342 & 0.733 \\
Age & -0.010 & 0.001 & 4.818 & 0.001 \\
Haemoglobin at baseline & -0.546 & 0.027 & -20.587 & 0.001 \\
\hline
\end{tabular}

the 30 schools in which children were offered a weekly iron tablet for 10 weeks, the haemoglobin concentration rose on average by $1.8 \mathrm{gl}^{-1}$ (Table 1 ) and the prevalence of anaemia fell by $8 \%$ (Table 2). The difference between the average rise in the treatment group and the average fall in the control group is only about $4 \%$ of the initial mean haemoglobin concentrations, nevertheless it represents a statistically significant improvement, brought about by iron tablets given by teachers, with the greatest benefit to the younger children and to girls.

Figure 2 indicates that the haemoglobin concentrations of all children who were anaemic at the start of the study tended to increase, and that iron had an additional effect. In contrast, the haemoglobin concentration of children who had an adequate haemoglobin concentration at baseline fell on average over the study period, but the fall was smaller in children who received iron. The impact of iron was consistent whether children were anaemic or not anaemic at the start of the study, suggesting that iron tablets benefited non-anaemic as well as anaemic children.

The data from the control group show that haemoglobin concentrations fell on average over the 4 months of the study period, perhaps because this coincided with the period between harvests in this part of Mali when there is a lack of food. Malaria is also endemic in Mali, although the study was done in the dry season when transmission is less intense than in the wet season ${ }^{10}$. But the fact that weekly iron apparently prevented a decline in haemoglobin concentrations over this period is encouraging and, as we have already said, girls benefited from the iron supplementation more than boys. This is important in a country where girls leave school early and get married when young.

Although daily iron supplements are in general more effective than weekly or biweekly iron ${ }^{11}$, there is growing evidence for a helpful role of intermittent iron supplements given to schoolchildren, particularly after treating parasitic infections that cause blood loss, such as hookworm. It may also be worthwhile giving a high potency capsule of vitamin A as well ${ }^{9}$, especially if iron supplements are given in the season when fruit and green leafy vegetables are not easily available. A previous study of adolescent children in Mali (reported by Beaton and
McCabe ${ }^{11}$ ) failed to reduce the overall prevalence of anaemia, which rose by $8 \%$ to $38 \%$ in the intervention group, almost the same as among a control group, although the prevalence of anaemia among adolescents given daily iron supplements fell from $37 \%$ to $31 \%{ }^{11}$. The different effect may reflect the fact that in the present study children were dewormed and given vitamin A before iron supplementation began, for reasons explained above. A study in rural Tanzania found that weekly iron supplements given to children after treatment for intestinal worms and urinary schistosomiasis led to significant improvements in serum ferritin concentration and body weight, but not in haemoglobin concentrations ${ }^{12}$, showing that other benefits may accrue. A study of weekly and twice weekly iron supplements given to Malaysian adolescent girls found increases in haemoglobin and ferritin concentrations, with the greatest increase occurring over the first 12 weeks of treatment ${ }^{13}$, confirming that effects can be achieved over quite a short period of supplementation.

The present study confirms that iron supplements given by teachers are a potential health intervention for children in non-formal schools in Mali after they have been dewormed and given vitamin A, especially for girls. The timing of the intervention to coincide with the period of lowest iron intake and good attendance rates at school will both be important. Perhaps greater improvements could be achieved, without placing too much of an extra burden on teachers, by giving iron twice a week or once a week for a longer period.

\section{Acknowledgements}

This study was funded by Save the Children, USA and Helen Keller International, Mali. The authors thank the communities, teachers and children for their collaboration, and the staff of the National Institute for Research in Public Health, the Kolondieba and local health centres.

\section{References}

1 Partnership for Child Development. Anaemia in schoolchildren in eight countries in Africa and Asia. Public Health Nutr. 2001; 4: 749-56.

2 Latham MC, Stephenson LS, Kinoti SN, Zaman MS, Kurz KM. Improvements in growth following iron supplementation in young Kenyan school children. Nutrition 1990; 6: 159-65.

3 Lawless JW, Latham MC, Stephenson LS, Kinoti SN, Pertet AM. Iron supplementation improves appetite and growth in anemic Kenyan primary school children. J. Nutr. 1994; 124: $645-54$.

4 Soemantri AG, Pollit E, Kim I. Iron deficiency anemia and educational achievement. Am. J. Clin. Nutr. 1985; 42 : $1221-8$.

5 Soewondo S, Husaini M, Pollit E. Effects of iron deficiency on attention and learning-processes in preschool-children Bandung, Indonesia. Am. J. Clin. Nutr. 1989; 50: 667-74.

6 Sacko M, De Clercq D, Behnke JM, Gilbert FS, Dorny P, Vercruysse J. Comparison of the efficacy of mebendazole, 
albendazole and pyrantel in treatment of human hookworm infections in the Southern Region of Mali, West Africa. Trans. Roy. Soc. Trop. Med. Hyg. 1999; 93: 195-203.

7 Sacko M, Roschnik N, Gorsline E. Evaluation de l'état de santé des enfants des écoles communautaires de Kolondiéba: Baseline Survey Report for School Health and Nutrition Programme. Bamako, Mali: Save the Children, USA, 1999.

8 WHO/UNICEF/IVACG Task Force. Vitamin A Supplements. $A$ Guide to their Use in the Treatment and Prevention of Vitamin A Deficiency and Xerophthalmia. Geneva: World Health Organization, 1997.

9 Mwanri L, Worsley A, Ryan P, Masika J. Supplemental vitamin A improves anemia and growth in anemic school children in Tanzania. J. Nutr. 2000; 130: 2691-6.

10 Bouvier P, Doumbo O, Breslow N, Robert CF, Mauris A, Picquet M, Kouriba B, Dembele HK, Dellwy V, Rougemont
A. Seasonality, malaria and impact of prophylaxis in a West African village I. Effect of anemia in pregnancy. Am.J. Trop. Med. Hyg. 1997; 56: 378-83.

11 Beaton GH, McCabe P. Efficacy of Intermittent Iron Supplementation in the Control of Iron Deficiency Anaemia in Developing Countries. An Analysis of Experience. Ottawa: The Micronutrient Initiative, 1999.

12 Beasley NM, Tomkins AM, Hall A, Lorri W, Kihamia C, Bundy DA. The impact of weekly iron supplementation on the iron status and growth of adolescent girls in Tanzania. Trop. Med. Int. Health 2000; 5: 794-9.

13 Tee E-S, Kandiah M, Awin N, Chong S-M, Satgunasingam N, Kamarudin L, Milani S, Dugdale AE, Viteri F. Schooladministered weekly iron-folate supplements improve hemoglobin and ferritin concentrations in Malaysian adolescent girls. Am. J. Clin. Nutr. 1999; 69: 1249-56. 